\title{
Expression of fibroblast growth factor-2 after application of the Queen's crepe-myrtle leaf (Lagerstroemia speciosa) and aloe vera extract gel in the wound healing process of hyperglycemic
}

\author{
Fachrul Razi ${ }^{1 *}$, Andri Hardianto², Lucky Riawan², Bambang Pontjo Priosoeryanto \\ ${ }^{1}$ Oral and Maxillofacial Surgery Clinics, Public Hospital of Majalengka, Indonesia \\ ${ }^{2}$ Department of Oral and Maxillofacial Surgery, Faculty of Dentistry Universitas Padjadjaran, \\ Indonesia
}

${ }^{3}$ Department of Veterinary Clinic Reproduction and Pathology, Faculty of Veterinary Medicine IPB University, Indonesia

\begin{abstract}
Introduction: Fibroblast Growth Factor-2 (FGF-2) have a role in stimulating the proliferation and migration of various types of cells in the wound healing process. Hyperglycemic conditions can disrupt the wound healing process. Lagerstroemia speciosa are known to have antyphyerglycemic and antioxidant effects. Aloe vera is a plant that has been used for long time in topical treatment of wounds. This study was aimed to analyse the FGF-2 after application of Queen's crepe-myrtle leaf (Lagerstroemia speciosa) and aloe vera extracts gel in the wound healing process of hyperglycemia. Methods: A pure experimental study was conducted with simple random sampling. The sample was 27 experimental animals (Cl 95\%; power test $80 \%$ ) of Sprague Dawley rat induced to have a hyperglycemic state using alloxan and had their palate injured. The immunohistochemical examination was performed to assess FGF-2 expression level. Samples were divided into three groups with a simple random sampling technique: nine of the rats received the Lagerstroemia speciosa extract gel application; nine rats received the aloe vera extract gel application on the injured palate; another nine rats in the control group. Examination of the FGF-2 expression level was performed on the third, seventh, and fourteenth observation days. Results: Overall, the control group had a significant difference with the Lagerstroemia speciosa and aloe vera extract gel group ( $\mathrm{p}$-value $<0.05$ ), however, the Lagerstroemia speciosa group did not have any significant difference with the aloe vera group $(0.123>0.05)$. Conclusion: There was no difference in the amount of FGF-2 expressions on the wound healing process of the injured palatal tissue of Sprague-Dawley rats with hyperglycemic after application of the Lagerstroemia speciosa and aloe vera extract gel.
\end{abstract}

Keywords: Lagerstroemia speciosa; Queen's crepe-myrtle; aloe vera; fibroblast growth factor-2; wound healing; hyperglycemic.

p-ISSN: 1979-0201; e-ISSN: 2549-6212; Available from: http://jurnal.unpad.ac.id/pjd/article/view/21276

DOI: 10.24198/pjd.vol33no1.21276

Submission: Apr 09, 2019; Accepted: Jan 05, 2021; Published online: Mar 31, 2021

"Corresponding author: Fachrul Razi, Oral and Maxillofacial Surgery Clinics, Public Hospital of Majalengka, Indonesia. 77, Jalan Kesehatan, Majalengka Wetan, West Java, Indonesia, 45411. Phone: +62 813-1991-1103; e-mail:drg_fachrulrazi1979@ yahoo.com 


\section{INTRODUCTION}

Wound healing is a complex and dynamic process, which physiologically will occur after damage to the skin layer. ${ }^{1}$ Wound healing process can be divided into three phases; inflammation, proliferation, and tissue remodeling. ${ }^{1}$ Wound healing is normally affected by both systemic and local conditions. ${ }^{1}$ Systemic factors include age, nutrition, trauma, metabolic disease, immunosuppression, connective tissue disorders, and smoking; while local factors include mechanical injury, infection, edema, tissue ischemia or necrosis, topical agents, ionizing radiation, lack of oxygen, and foreign bodies. ${ }^{1}$

Fibroblast growth factor-2 (FGF-2) is a signalcarrying protein consisting of many polypeptides to stimulate proliferation and migration of various cell types in wound healing. ${ }^{3,4}$ These cells include capillary endothelial cells, vascular endothelial cells, fibroblasts, keratinocytes, epithelial cells, and some special cells such as chondrocytes and myoblasts. ${ }^{3}$ FGF-2 can also stimulate collagen synthesis, epithelialization, and fibronectin and proteoglycan synthesis. In addition, FGF-2 can induce cell migration, neovascularization, and granulation cell formation. ${ }^{4}$

In diabetics, there can be interference in the wound healing process. The uncontrolled hyperglycemic condition in diabetes can reduce inflammatory processes, angiogenesis, and collagen synthesis in wound healing. ${ }^{2}$ Hyperglycemic condition can reduce the function of red blood cells that carry nutrients to the tissues, as well as reduce the efficiency of leukocytes in fighting infection. ${ }^{2}$ Narrowing of blood vessels can cause decreased blood flow and oxygen to the wound, so that without adequate nutrition and oxygen, wound healing will occur slowly. ${ }^{4}$ For better wound healing in diabetic patients, it is generally necessary to improve blood sugar level, administration of adequate antibiotics, and improve other metabolic disorders. ${ }^{5}$

Along with the increasing public awareness about the potential and side effects of synthetic drugs, there is an increasing interest in natural remedies. Herbal plants are known to contain many chemical compounds that are needed by the human body to treat disease or promote health and well-being. Currently, about $80 \%$ of people in developing countries still rely on traditional medicine. ${ }^{6}$

One plant known for its benefits as herbal medicine is the Queen's crepe-myrtle (Lagerstroemia speciosa). ${ }^{7}$ L. speciosa is known to have antihyperglycemic and antioxidant effects. L. speciosa also known to have antiinflamtory, antibacterial and antiviral activity. ${ }^{7}$ Aloe vera is a plant that also has long been used for topical treatment for various wounds. ${ }^{8,9}$ Aloe vera can stimulate the proliferation of several cell types, many studies have shown that Aloe vera extract will accelerate the wound healing process. ${ }^{8}$ Aloe vera can have a direct effect on wound healing by increasing wound contraction and collagen synthesis. ${ }^{8,9}$

There have been no studies conducted on the wound healing process in people with diabetes using $L$. speciosa as the common natural remedy for diabetes and aloe vera as the common natural remedy for wound healing. This study was aimed to analyse the FGF-2 after application of Queen's crepe-myrtle leaf (Lagerstroemia speciosa) and aloe vera extracts gel in the wound healing process of hyperglycemia.

\section{METHODS}

Pure experimental research $(95 \% \mathrm{Cl} ; 80 \%$ power test). was conducted on 27 experimental animals (Sprague-Dawleyrats). This research wasconducted at the Pharmacy Laboratory of IPB University. The research phase towards experimental animals was carried out at the Teaching Animal Hospital of IPB University, and immunohistochemical examination was conducted at the Department of Anatomical Pathology, Faculty of Medicine Universitas Padjadjaran - Hasan Sadikin Hospital Bandung. The ethical clearance has obtained from IPB University with the approval number of 127-2018 IPB.

\section{Experimental animals}

The Sprague-Dawley rats sample were kept at the Teaching Animal Hospital of the Faculty of Veterinary Medicine IPB University. Inclusion criteria: male Sprague-Dawley rats, healthy, had an average body weight of 200-300 grams, aged eight weeks, and had been quarantined-exclusion criteria: rats that died during the adaptation and study period and paralysed rats. 


\section{Lagerstroemia speciosa and aloe vera extracts gel}

Lagerstroemia speciosa and aloe vera extracts gel were fabricated at the Pharmacy Laboratory of IPB University. The Queen's crepe-myrtle leaves were dried, cut into small pieces, then blended into a powder. Extraction was carried out by adding $200 \mathrm{ml}$ of $96 \%$ ethanol into a boiling flask, adding 20 grams of powder, boiling the mixture at $35^{\circ} \mathrm{C}$, and then filtering it using gauze. Evaporation was performed using a rotary evaporator to remove ethanol and then dried at $50^{\circ} \mathrm{C}$ until a dry extract was obtained. The gel was made using $2 \%$ Carbopol 934 as an oral base gel emulsion base with $10 \%$ of powdered Queen's crepe-myrtle leaf and stored in a sterile place in a refrigerator at $4^{\circ} \mathrm{C}$ until time usage.

\section{Groups and treatments}

Sprague-Dawley rats were induced by single intravenous alloxan in the peritoneum with a dose of $100 \mathrm{mg} / \mathrm{kg}$ BW until they reached a hyperglycemic state where their blood sugar levels increased to $>110 \mathrm{mg} / \mathrm{dL}$ after undergoing quarantine for 10-14 days. ${ }^{10}$ The wounds were made on the anterior hard palate using a punch biopsy of $0.5 \mathrm{~cm}$ so that the magnitude of the wound was evenly distributed for all rats. A total of 27 rats were divided into three treatment groups, and each group consisted of 9 rats. The negative control group was not given topical application; the second group was the positive control group which was given topical application of aloe vera extract gel to the palate; the third group was given Queen's crepe-myrtle extract gel three times a day in the same way. Each group was divided into three observation times: the third, seventh, and fourteenth days after treatment. On these days, the rats were necropsied, then post-wound palate tissue was taken and made preparations.

\section{Immunohistochemical examination}

An immunohistochemical examination was conducted by PT. Biozatix Indonesia to assess the level of fibroblast growth factor-2 (FGF2) expression. The scoring criteria for FGF2 expression was in accordance with the immunoreactive score. The table was then converted into a histoscore calculation. Scoring of cell distribution was assessed as follows: No cells immunoreactive (score 0 ); $<20 \%$ cells immunoreactive (1); 20-50\% (2); $50-80 \%$ (3); >80\% (4). Color intensity scoring: None colored (score 0 ); weak positive/pale brown (1); medium positive/ light brown (2); strong positive/dark brown (3). Histoscore interpretation: 0 (no expression); 1-3 (weak expression); 4-8 (medium expression); 9-12 (strong expression). ${ }^{11}$

\section{Statistic analysis}

Statistical analysis was performed using the Kruskal Wallis test. a.

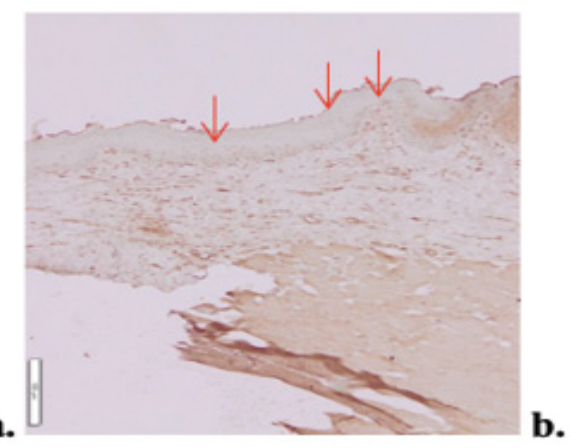

Figure 1. Histopathological features of FGF-2 expression on the third day. a) Control group, b) Aloe vera extract gel group, c) Langerstroemia speciosa extract gel group

\section{RESULTS}

On the results of the seventh day observation, began to show a difference in the level of FGF-2 expression, where the group with Queen's crepe- myrtle leaf extract gel was more dominant than the aloe vera extract gel group.

On the $14^{\text {th }}$ day of observation, the group with Queen's crepe-myrtle leaf extract gel showed comparable levels of fibroblast growth factor 
a.

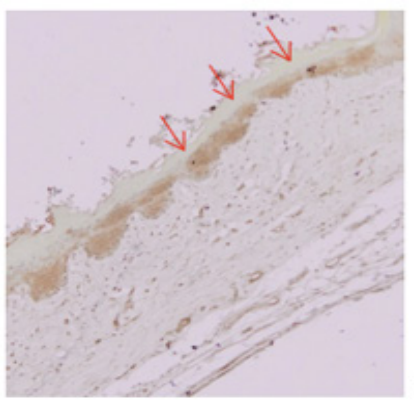

b.

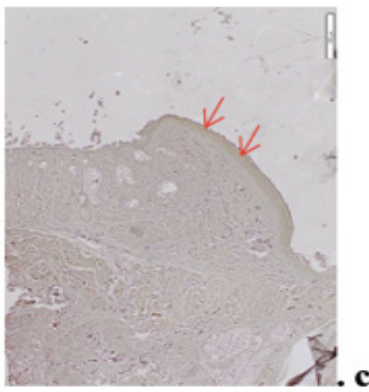

Figure 2. Histopathological features of FGF-2 expression on the seventh day. a) Control group, b) Aloe vera extract gel group, c) Lagerstroemia speciosa extract gel group

a.

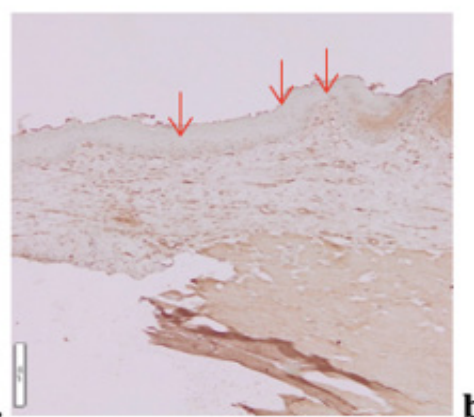

b.

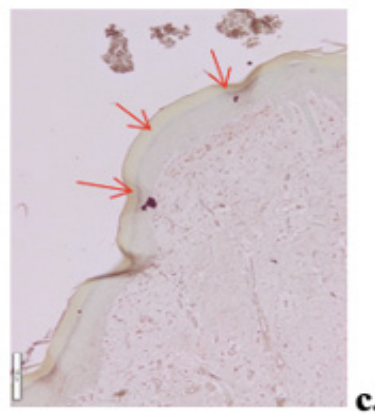

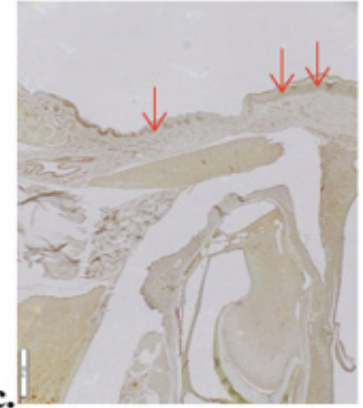

Figure 3. Histopathological features of FGF-2 expression at day 14. a) Control group, b) Aloe vera extract gel group, c) Lagerstroemia speciosa extract gel group

Table 1. The level of fibroblast growth factor-2 (FGF-2) expression between the application of Queen's crepe-myrtle (Lagerstroemia speciosa) and aloe vera extracts gel on the third, seventh, and fourteenth observation days

\begin{tabular}{|c|c|c|c|}
\hline Variable & Control & $\begin{array}{c}\text { Lagerstroemia speciosa } \\
\text { extract gel }\end{array}$ & Aloe vera extract gel \\
\hline \multicolumn{4}{|l|}{ FGF-2 (D-3) } \\
\hline No expression & $0(0.0 \%)$ & $0(0.0 \%)$ & $0(0.0 \%)$ \\
\hline Weak expression & $2(66.7 \%)$ & $0(0.0 \%)$ & $0(0.0 \%)$ \\
\hline Medium expression & $1(33.3 \%)$ & $2(66.7 \%)$ & $3(100.0 \%)$ \\
\hline Strong expression & $0(0.0 \%)$ & $1(33.3 \%)$ & $0(0.0 \%)$ \\
\hline \multicolumn{4}{|l|}{ FGF-2 (D-7) } \\
\hline No expression & $0(0.0 \%)$ & $0(0.0 \%)$ & $0(0.0 \%)$ \\
\hline Weak expression & $3(100.0 \%)$ & $1(33.3 \%)$ & $0(0.0 \%)$ \\
\hline Medium expression & $0(0.0 \%)$ & $0(0.0 \%)$ & $3(100.0 \%)$ \\
\hline Strong expression & $0(0.0 \%)$ & $2(66.7 \%)$ & $0(0.0 \%)$ \\
\hline \multicolumn{4}{|l|}{ FGF-2 (D-14) } \\
\hline No expression & $0(0.0 \%)$ & $0(0.0 \%)$ & $0(0.0 \%)$ \\
\hline Weak expression & $2(66.7 \%)$ & $0(0.0 \%)$ & $0(0.0 \%)$ \\
\hline Medium expression & $1(33.3 \%)$ & $1(33.3 \%)$ & $3(100.0 \%)$ \\
\hline Strong expression & $0(0.0 \%)$ & $2(66.7 \%)$ & $0(0.0 \%)$ \\
\hline
\end{tabular}


Table 2. The level of FGF-2 expression in the three group per observation day

\begin{tabular}{|c|c|c|c|c|}
\hline Variable & Control & $\begin{array}{c}\text { Lagerstroemia speciosa } \\
\text { extract gel }\end{array}$ & Aloe vera extract gel & $\mathrm{p}$-value \\
\hline \multicolumn{5}{|l|}{ FGF-2 (D-3) } \\
\hline$(\mathrm{SD})$ & $3.33(0.58)$ & $8.0(4.0)$ & $8.0(0.0)$ & 0.069 \\
\hline Median & 3 & 8 & 8 & \\
\hline Range & $3.0-4.0$ & $4.0-12.0$ & $8.0-8.0$ & \\
\hline \multicolumn{5}{|l|}{ FGF-2 (D-7) } \\
\hline$(\mathrm{SD})$ & $3.00(0.00)$ & $9.00(5.20)$ & $7.33(1.15)$ & 0.121 \\
\hline Median & 3 & 12 & 8 & \\
\hline Range & $3.0-9.0$ & $3.0-12.0$ & $6.0-8.0$ & \\
\hline \multicolumn{5}{|l|}{ FGF-2 (D-14) } \\
\hline$(\mathrm{SD})$ & $3.00(1.00)$ & $10.67(2.31)$ & $7.33(1.15)$ & $0.034^{(\mathrm{a})}$ \\
\hline Median & 3 & 12 & 7 & \\
\hline Range & $2.0-4.0$ & $8.0-12.0$ & $6.0-8.0$ & \\
\hline
\end{tabular}

Different superscript letters on the same line indicate significant differences $(p<0.05)$ based on the Kruskal-Wallis test

expression with the aloe vera extract gel group (Figure 3).

Table 2 showed a significant difference in the FGF-2 expression level in at least a pair of treatment groups on the fourteenth observation day (p-value $<0.05)$. Meanwhile, on the third and seventh days, there was no difference in the FGF2 expression level of the three treatment groups. The Mann-Whitney test was conducted afterwards to determine which groups had a significant

Table 3. Mann-Whitney test results of measure time $14^{\text {th }}$ day

\begin{tabular}{cllc}
\hline \multirow{2}{*}{ Measurement time } & Comparison & $\mathrm{p}$-value \\
\hline \multirow{2}{*}{$14^{\text {th }}$ day } & Control & Lagerstroemia speciosa & 0.046 \\
& & Aloe vera & 0.046 \\
\cline { 2 - 4 } & Lagerstroemia speciosa & Aloe vera & 0.099 \\
\hline
\end{tabular}

difference. The level of fibroblast growth factor-2 (FGF-2) expression on the third day in the group

The calculation results showed that the control group was significantly different from the Lagerstroemia speciosa and aloe vera extracts gel group $(0.046<0.05)$. The FGF-2 expression of the Lagerstroemia speciosa extracts gel group, however, was not significantly different from the aloe vera extracts gel group $(0.099>0.05)$, which indicated that the effectiveness of the Lagerstroemia speciosa extracts was almost similar with the aloe vera extracts, higher average found in the Lagerstroemia speciosa extracts gel group.

The analysis results on the hypothesis test of total observation day showed significant differences in the three treatment groups (Table 4). Afterwards, the Mann-Whitney test

Table 4. The level of FGF-2 expression in the three group of total observation day

\begin{tabular}{lcccc}
\hline \multicolumn{1}{c}{ Variable } & Control & $\begin{array}{c}\text { Lagerstroemia speciosa } \\
\text { extract gel }\end{array}$ & Aloe vera extract gel & p-value \\
\hline FGF-2 (Total observation day) & & & & \\
$\bar{X}(\mathrm{SD})$ & $3.11(0.60)$ & $9.22(3.67)$ & $7.56(0.73)$ & $0.000^{(\mathrm{a})}$ \\
Median & 3 & 12 & 8 & $6.0-8.0$ \\
Range & $2.0-4.0$ & $3.0-12.0$ & \\
\hline
\end{tabular}




\begin{tabular}{|c|c|c|c|}
\hline Measurement time & & iparison & $\mathrm{p}$-value \\
\hline \multirow[t]{4}{*}{ Total observation day } & Control & Lagerstroemia speciosa & 0.001 \\
\hline & & Aloe vera & 0.000 \\
\hline & Lagerstroemia speciosa & Control & 0.001 \\
\hline & & Aloe vera & 0.139 \\
\hline
\end{tabular}

was conducted to determine which group has a significant difference.

The calculation results showed that the control group was significantly different from the Lagerstroemia speciosa and the aloe vera extracts gel group ( $p$-value $<0.05)$. However, the FGF expression for the Lagerstroemia speciosa extracts gel group was not significantly different from the aloe vera $(0.139>0.05)$, meaning that the effectiveness of the Lagerstroemia speciosa was quite similar with the aloe vera extract gel, with a higher average for the Lagerstroemia extracts gel group.

\section{DISCUSSION}

Wound healing is complex process involves various components, keratinocytes, fibroblasts, vascular endothelial cells, immune cells and the related extracellular matrix. ${ }^{1}$ Hyperglycemia can interfere with the regulation of cellular functions, such as defective T-cell immunity, abnormalities in leukocyte chemotaxis, phagocytosis, bactericides, and fibroblast and epidermal cell dysfunction. ${ }^{2}$

The present study results showed that Lagerstroemia speciosa and aloe vera extracts gel's application affected the wound healing process in the palate of hyperglycemic rats compared to the untreated group. This result was proofed from the significant differences in the FGF-2 expression level in the Lagerstroemia speciosa and aloe vera extracts gel group on the fourteenth observation day ( $p$-value $<0.05)$. Although on the third and seventh days found no difference in the FGF-2 expression level between the three groups.

Fibroblast Growth Factor-2 (FGF-2) functions to stimulate the proliferation and migration of various wound healing cells invitro or in-vivo. ${ }^{3}$ These cells included capillary endothelial cells, vascular endothelial cells, fibroblasts, keratinocytes, epithelial cells, and some particular cells such as chondrocytes and myoblasts. ${ }^{3,4}$ FGF-2 can also stimulate collagen synthesis, epithelialisation, and also fibronectin and proteoglycan synthesis. ${ }^{3,4}$ Also, FGF-2 can induce cell migration, neovascularisation, and granulation cell formation. ${ }^{4}$ The present study showed that the FGF-2 expression level of the Lagerstroemia speciosa extracts gel group was not significantly different from the aloe vera $(0.139>0.05)$. This result indicated that the effectiveness of the Lagerstroemia speciosa extracts gel was quite similar to aloe vera $(0.139>0.05)$, with a higher FGF-2 expression level.

There are still no studies that directly examine the effect of Lagerstroemia speciosa in increasing the FGF expression levels on the wound healing process until the present. Lagerstroemia speciosa, commonly called banaba or jarul, is commonly used to cure various diseases such as diabetes, obesity, and kidney function disorders. ${ }^{12}$ Pharmacologically, this plant has various effects, such as antimicrobial activity, anti-inflammatory, antioxidant, antitussive, cytotoxic activity, antiobesity, anti-diabetic, anti-fibrotic, xanthine oxidase inhibition, and antiviral activity. ${ }^{13,14}$

Wound healing begins with microbial cleaning; thus, this process will be helped by the Lagerstroemia speciosa extract due to its role in killing bacteria and viruses. ${ }^{12,13}$ The antiinflammatory effect of Lagerstroemia speciosa can also maximize the wound healing process. ${ }^{13}$ The hypoglycemic effect of Lagerstroemia speciosa is also strongly associated with maximum wound healing. Lagerstroemin, flosin $B$, and reginin are also found in the Lagerstroemia speciosa leaf extract, which can increase blood glucose uptake to adipocyte cells and reduce blood glucose levels. ${ }^{7,14}$ The content of corosolic acid can reduce blood sugar levels. ${ }^{7,14}$ Aloe vera is a plant that has long been used for the topical treatment of 
various wounds and burns in various countries. ${ }^{8,9}$ Aloe vera can stimulate the proliferation of several types of cells. Many studies have shown that aloe vera extract will accelerate the wound healing process. Aloe vera can directly affect wound healing by increasing wound contraction and collagen synthesis due to the content of mannose-6-phosphate in aloe vera extract. ${ }^{9,15}$

The polysaccharide content in aloe vera can also increase fibroblast proliferation and produce hyaluronic acid and hydroxyproline in the fibroblasts, which play an essential role in remodelling the extracellular matrix in wound healing. ${ }^{15}$ Previous study concluded that aloe vera gel could reduce wound diameter by $62.5 \%$ in rats given aloe vera gel at a dose of $100 / \mathrm{mg} /$ $\mathrm{kg} /$ day and a decrease in the wound diameter by $50.8 \%$ in rats given topical $25 \%$ aloe vera gel. ${ }^{16}$ The research conducted by Kayode ${ }^{17}$ on rabbits also showed a similar result. An aloe vera extract given to the rabbit wounds had significantly affected the wound contraction, especially in the proliferative and maturation phases. ${ }^{17}$

There are also no studies that directly examine the effect of aloe vera extract in increasing the FGF expression levels on the wound healing process of hyperglycemic. Therefore, the present study is the first study that examined and compared the effects of Lagerstroemia speciosa and aloe vera on hyperglycemia-induced rats' wound healing process by observing the FGF-2 expression level. Further research is needed to see the effect of both natural remedies on the wound healing process of hyperglycemic.

\section{CONCLUSION}

There was no difference in the effect of the application of the Queen's crepe-myrtle (Lagerstroemia speciosa) and aloe vera extract gel on the wound healing process of Sprague-Dawley rats with hyperglycemic from the observation of the amount of fibroblast growth factor-2 expressions in the injured palatal tissue.

\section{REFERENCES}

1. Martin P, Nunan R. Cellular and molecular mechanisms of repair in acute and chronic wound healing. $\mathrm{Br}$ J Dermatol. 2015; 173(2):
370-8. DOI: $10.1111 /$ bjd.13954

2. Marchianti ACN, Sakinah EN, Elfiah U, Putri NKS, Wahyuliswari DI, Maulana $M$, et al. Gel formulations of Merremia mammosa (Lour.) accelerated wound healing of the wound in diabetic rats. J Tradit Complement Med. 2019; 11(1): 38-45. DOI: 10.1016/j. jtcme.2019.12.002

3. Nunes QM, Li Y, Sun C, Kinnunen TK, Fernig DG. Fibroblast growth factors as tissue repair and regeneration therapeutics. Peer J. 2016; 4: e1535. DOI: $10.7717 /$ peerj.1535

4. Edamura K, Takahashi $\mathrm{Y}$, Fujii A, Masuhiro $\mathrm{Y}$, Narita T, Seki $M$, et al. Recombinant canine basic fibroblast growth factor-induced differentiation of canine bone marrow mesenchymal stem cells into voltage and glutamate-responsive neuron-like cells. Regen Ther. 2020; 15: 121-128. DOI: 10.1016/j. reth.2020.07.005

5. Brunicardi FC, Andersen DK, Billiar TR, Dunn DL, Hunter JG, et al. Schwartz's Principles of Surgery. $10^{\text {th }}$ ed. New York: McGraw-Hill Education; 2015. p. 241-66.

6. Nilugal KC, Perumal K, Ugander RE, Chittor Al. Evaluation of wound healing activity of Piper betle leaves and stem extract in experimental Wistar rats. Am J Pharm Res. 2014; 4(3): 44352.

7. Nurcahyanti ADR, Arieselia Z, Kurniawan SV, Sofyan F, Wink M. Revisiting Bungur (Lagerstroemia speciosa) from Indonesia as an antidiabetic agent, its mode of action, and phylogenetic position. Pharmacogn Rev. 2018; 12(23): 40-5. DOI: 10.4103/phrev.phrev_20_17

8. Hormozi M, Assaei R, Boroujeni MB. The effect of aloe vera on the expression of wound healing factors (TGFB1 and bFGF) in mouse embryonic fibroblast cell: In vitro study. Biomed Pharmacother. 2017; 88: 610-6. DOI: 10.1016/j.biopha.2017.01.095

9. Radha MH, Laxmipriya NP. Evaluation of biological properties and clinical effectiveness of Aloe vera: A systematic review. J Tradit Complement Med. 2015; 5(1): 21-6. DOI: 10.1016/j.jtcme.2014.10.006

10. Torregroza C, Feige K, Schneider L, Bunte S, Stroethoff $M$, Heinen $A$, et al. Influence of hyperglycemia on dexmedetomidine-induced cardioprotection in the isolated perfused 
rat heart. J Clin Med. 2020; 9(5): 1445. DOI: $10.3390 / \mathrm{jcm} 9051445$

11. Fedchenko N, Reifenrath J. Different approaches for interpretation and reporting of immunohistochemistry analysis result in the bone tissue-A review. Diagn Pathol. 2014; 9: 221. DOI: 10.1186/s13000-014-0221-9

12. Nilugal KC, Perumal K, Ugander RE, Chittor Al. Evaluation of wound healing activity of Piper betle leaves and stem extract in experimental Wistar rats. Am J Pharm Tech Res. 2014; 4(3): 443-52.

13. Pal M, Thareja D, Majee C. Lagerstroemia species: A review. Int J Pharm. 2016; 6(1): 95 8.

14. Chan EWC, Tan LN, Wong SK. Phytochemistry and pharmacology of Lagerstroemia speciosa: A natural remedy for diabetes. Int J Herb Med. 2014; 2(1): 81-7.

15. Hashemi SA, Madani SA, Abediankenari S. The review on properties of Aloe vera in healing of cutaneous wounds. BioMed Res Int. 2015; 2015: 714216. DOI: 10.1155/2015/714216

16. Mohamed EAK. Antidiabetic, antihypercholestermic and antioxidative effect of aloe vera gel extract in alloxan induced diabetic rats. Aust J Basic Appl Sci. 2011; 5(11): 1321-7.

17. Kayode OA. Effects of aloe vera gel application on epidermal wound healing in the domestic rabbit. Int J Res Med Sci. 2017; 5(1): 101-5. DOI: $10.18203 / 2320-6012 . i j r m s 20164531$ 